\title{
ORIGINAL
}

\section{Determinants of the effect of extracorporeal carbon dioxide removal in the SUPERNOVA trial: implications for trial design}

\author{
Ewan C. Goligher ${ }^{1,2,3^{*}} \mathbb{(}$, Alain Combes ${ }^{4}$, Daniel Brodie ${ }^{5,6}$, Niall D. Ferguson 1,2,3,7,8, Antonio M. Pesenti ${ }^{9,10}$, \\ V. Marco Ranieri ${ }^{11}$, Arthur S. Slutsky ${ }^{1,12}$ and for the SUPERNOVA investigators (European Society of Intensive \\ Care Medicine trials group) and for the International ECMO Network (ECMONet)
}

(c) 2019 Springer-Verlag GmbH Germany, part of Springer Nature

\begin{abstract}
Purpose: To describe the variability and determinants of the effect of extracorporeal $\mathrm{CO}_{2}$ removal $\left(\mathrm{ECCO}_{2} \mathrm{R}\right)$ on tidal volume $\left(V_{t}\right)$, driving pressure $(\Delta P)$, and mechanical power $\left(\right.$ Power $\left._{R S}\right)$ and to determine whether highly responsive patients can be identified for the purpose of predictive enrichment in $\mathrm{ECCO}_{2} \mathrm{R}$ trial design.

Methods: Using data from the SUPERNOVA trial (95 patients with early moderate acute respiratory distress syndrome), the independent effects of alveolar dead space fraction (ADF), respiratory system compliance (Crs), hypoxemia $\left(\mathrm{PaO}_{2} / \mathrm{FiO}_{2}\right)$, and device performance (higher vs lower $\mathrm{CO}_{2}$ extraction) on the magnitude of reduction in $V_{t}, \triangle P$, and Power $_{\mathrm{RS}}$ permitted by $\mathrm{ECCO}_{2} \mathrm{R}$ were assessed by linear regression. Predicted and observed changes in $\triangle P$ were compared by Bland-Altman analysis. Hypothetical trials of $\mathrm{ECCO}_{2} \mathrm{R}$, incorporating predictive enrichment and different target $\mathrm{CO}_{2}$ removal rates, were simulated in the SUPERNOVA study population.

Results: Changes in $V_{\mathrm{t}}$ permitted by $\mathrm{ECCO}_{2} \mathrm{R}$ were independently associated with $\mathrm{ADF}$ and device performance but not $\mathrm{PaO}_{2} / \mathrm{FiO}_{2}$. Changes in $\triangle P$ and Power ${ }_{\mathrm{RS}}$ were independently associated with $\mathrm{ADF}, \mathrm{Crs}$, and device performance but not $\mathrm{PaO}_{2} / \mathrm{FiO}_{2}$. The change in $\triangle P$ predicted from ADF and $\mathrm{Crs}$ was moderately correlated with observed change in $\triangle P$ $\left(R^{2} 0.32, p<0.001\right)$; limits of agreement between observed and predicted changes in $\triangle P$ were $\pm 3.9 \mathrm{cmH}_{2} \mathrm{O}$. In simulated trials, restricting enrollment to patients with a larger predicted decrease in $\triangle P$ enhanced the average reduction in $\Delta P$, increased predicted mortality benefit, and reduced sample size and screening size requirements. The increase in statistical power obtained by restricting enrollment based on predicted $\triangle P$ response varied according to device performance as specified by the target $\mathrm{CO}_{2}$ removal rate.
\end{abstract}

\footnotetext{
*Correspondence: ewan.goligher@utoronto.ca

${ }^{1}$ Interdepartmental Division of Critical Care Medicine, University

of Toronto, Toronto, Canada

Full author information is available at the end of the article
}

V. Marco Ranieri and Arthur S. Slutsky are contributing senior authors.

Members of the SUPERNOVA trial are listed in Acknowledgements

The SUPERNOVA trial (Strategy of Ultra-Protective Lung Ventilation with extracorporeal $\mathrm{CO}_{2}$ removal for new-onset Moderate to severe ARDS) was supported by the European Society of Intensive Care Medicine and endorsed by the International ECMO Network (ECMONet).

\section{实 Springer}


Conclusions: The lung-protective benefits of $\mathrm{ECCO}_{2} \mathrm{R}$ increase with higher alveolar dead space fraction, lower respiratory system compliance, and higher device performance. ADF and Crs, rather than severity of hypoxemia, should be the primary factors determining whether to enroll patients in clinical trials of $\mathrm{ECCO}_{2} \mathrm{R}$.

Keywords: Acute respiratory distress syndrome, Extracorporeal carbon dioxide removal, Artificial ventilation, Ventilator-induced lung injury, Predictive enrichment

\section{Introduction}

In patients with acute respiratory distress syndrome (ARDS), lowering tidal volume $\left(V_{\mathrm{t}}\right)$ and driving pressure (i.e. end-inspiratory plateau pressure minus positive endexpiratory pressure: $\Delta P$ ) to reduce pulmonary stress and strain can decrease ventilator-induced lung injury and improve survival [1-3]. However, lowering $V_{\mathrm{t}}$ is often associated with respiratory acidosis, even if respiratory rate (RR) is increased, and there is evidence that hypercapnia along with the use of high RR may worsen clinical outcomes $[1,2]$.

Removing carbon dioxide via an external membrane lung (extracorporeal $\mathrm{CO}_{2}$ removal, $\mathrm{ECCO}_{2} \mathrm{R}$ ) can attenuate respiratory acidosis, permitting greater reductions in $V_{\mathrm{t}}, \Delta P$, and RR [3, 4], and thereby may improve outcomes in ARDS. $\mathrm{ECCO}_{2} \mathrm{R}$, however, is invasive, costly, and carries significant risks including hemorrhage, hemolysis, and thrombosis [5]. Applying $\mathrm{ECCO}_{2} \mathrm{R}$ to reduce $V_{\mathrm{t}}$ to very low levels may also worsen lung mechanics by increasing atelectasis. To optimize the balance of benefit and risk, $\mathrm{ECCO}_{2} \mathrm{R}$ should ideally be applied specifically to patients who stand to accrue the greatest clinical benefit [6].

Based on a theoretical analysis of physiological equations defining alveolar ventilation [6], we hypothesize that for a given $\mathrm{PaCO}_{2}$ the reduction in $V_{\mathrm{t}}, \Delta P$, and mechanical power $\left(\right.$ Power $_{R S}$ ) enabled by $\mathrm{ECCO}_{2} \mathrm{R}$ depends on specific patient physiological characteristics [i.e., alveolar dead space fraction (ADF) and respiratory system compliance $(\mathrm{Crs})]$, and on the $\mathrm{CO}_{2}$ clearance rate achieved by the $\mathrm{ECCO}_{2} \mathrm{R}$ device. In the current study, we aimed to test this hypothesis using data from the SUPERNOVA trial [7] to inform the design of a future trial of $\mathrm{ECCO}_{2} \mathrm{R}$.

\section{Methods}

\section{The SUPERNOVA trial}

SUPERNOVA was a pilot trial evaluating the efficacy and safety of $\mathrm{ECCO}_{2} \mathrm{R}$ to achieve ultra-protective ventilation $\left(V_{\mathrm{t}}\right.$ of $4 \mathrm{ml} / \mathrm{kg}$ predicted body weight [PBW]) in 95 patients with moderate ARDS $\left(100<\mathrm{PaO}_{2} /\right.$ $\mathrm{FiO}_{2} \leq 200 \mathrm{mmHg}$ ) from 23 centers [7]. At different centers $\mathrm{ECCO}_{2} \mathrm{R}$ was applied using either the Hemolung Respiratory Assist System (ALung Technologies,

\section{Take-home messages}

The lung-protective benefits of $\mathrm{ECCO}_{2} \mathrm{R}$ increase with higher alveolar dead space fraction, lower respiratory system compliance, and higher device performance. Alveolar dead space fraction and respiratory system compliance, rather than severity of hypoxemia, should be the primary factors determining whether to enroll patients in clinical trials of $\mathrm{ECCO}_{2} \mathrm{R}$. Restricting enrollment based on the predicted treatment effect may enhance statistical power in a future trial of $\mathrm{ECCO}_{2} \mathrm{R}$.

Pittsburgh, USA), the iLA Activve (Xenios, Heilbronn, Germany), or the Cardiohelp ${ }^{\circledR}$ HLS 5.0 (GETINGE Cardiopulmonary Care, Rastatt, Germany). The first device (lower $\mathrm{CO}_{2}$ extraction device) employs a membrane lung with a cross-sectional area of $0.59 \mathrm{~m}^{2}$ and is run at an extracorporeal blood flow between 300 and $500 \mathrm{ml} / \mathrm{min}$. The other two devices (higher $\mathrm{CO}_{2}$ extraction devices) employ membrane lungs of $1.30 \mathrm{~m}^{2}$; in the trial they were operated with blood flows of $800-1000 \mathrm{ml} / \mathrm{min}$. The primary endpoint in the trial was the number of patients who successfully achieved a $V_{\mathrm{T}}$ of $4 \mathrm{ml} / \mathrm{kg} \mathrm{PBW}$ with arterial $\mathrm{pH}>7.30$ and $\mathrm{PaCO}_{2}$ not increasing more than $20 \%$ relative to baseline condition (where $V_{\mathrm{T}}$ was set at $6 \mathrm{ml} / \mathrm{kg}$ PBW, positive end-expiratory pressure (PEEP) was adjusted to obtain an end-inspiratory plateau airway pressure $\left(\mathrm{P}_{\text {PLAT }}\right.$ ) between 28 and $30 \mathrm{cmH}_{2} \mathrm{O}$, and sweep gas flow was set to $0 \mathrm{l} / \mathrm{min}$ ).

\section{Physiological computations}

Crs, anatomical dead space volume, ADF [6], ventilatory ratio (VR) [8], and Power $_{\mathrm{RS}}$ [9] were calculated as previously described using relevant physiological variables collected at baseline. Computations are detailed in the Online Supplement.

\section{Quantifying the effect of $\mathrm{ECCO}_{2} \mathrm{R}$}

There were two discrete interventions in SUPERNOVA: first, reductions in $V_{\mathrm{t}}$ permitted by $\mathrm{ECCO}_{2} \mathrm{R}$, and second, reductions in $V_{\mathrm{t}}$ enabled by more permissive ventilation targets for $\mathrm{PaCO}_{2}$ (allowed to increase by up to $20 \%$ to achieve the $V_{\mathrm{t}} 4 \mathrm{ml} / \mathrm{kg}$ ). To isolate the effect of $\mathrm{ECCO}_{2} \mathrm{R}$ on $V_{\mathrm{t}}$ independent of the change in $\mathrm{PaCO}_{2}$ target and to enable comparisons of treatment effect between patients, $V_{\mathrm{t}}$ before $\mathrm{ECCO}_{2} \mathrm{R}$ (at the moment before sweep gas flow commenced) and after $\mathrm{ECCO}_{2} \mathrm{R}$ (once the $4 \mathrm{ml} / \mathrm{kg}$ step 
was reached) were normalized to the $V_{\mathrm{t}}$ that would have been required to obtain a $\mathrm{PaCO}_{2}$ of $45 \mathrm{mmHg}$ at $\mathrm{RR}$ of 30 breaths $/ \mathrm{min}$. Power ${ }_{\mathrm{RS}}$ was standardized for a $\mathrm{PaCO}_{2}$ of $45 \mathrm{mmHg}$. Computations are described in detail in the Online Supplement.

The effect of $\mathrm{ECCO}_{2} \mathrm{R}$ was also quantified in terms of the probability of reaching the SUPERNOVA trial primary end-point at $8 \mathrm{~h}$ after initiating $\mathrm{ECCO}_{2} \mathrm{R}$.

\section{Determinants of the effect of $\mathrm{ECCO}_{2} \mathrm{R}$}

Baseline characteristics were compared between patients with smaller $(<$ median) or larger ( $>$ median) changes in standardized $\Delta P$ after applying $\mathrm{ECCO}_{2} \mathrm{R}$. Device performance was classified according to expected $\mathrm{CO}_{2}$ extraction capability (lower-Hemolung; higher-Cardiohelp and iLA activve) based on previously reported $\mathrm{CO}_{2}$ removal rates [10]. The independent effects of patient physiological characteristics $\left(\mathrm{PaO}_{2} / \mathrm{FiO}_{2}, \mathrm{ADF}, \mathrm{VR}, \mathrm{Crs}\right)$ and device performance (lower vs. higher $\mathrm{CO}_{2}$ extraction) on the change in standardized values of $V_{\mathrm{t}}, \Delta P$, and Power $_{\mathrm{RS}}$ obtained by applying $\mathrm{ECCO}_{2} \mathrm{R}$ were evaluated using pre-specified bivariate and multiple linear regression models (see Table E1 for description of multivariable models). The effects of these characteristics on the probability of achieving the primary endpoint was evaluated using multivariable logistic regression (see Table E1 for description of model).

\section{Predicting the effect of $\mathrm{ECCO}_{2} \mathrm{R}$ on driving pressure}

We previously showed that the reduction in $\Delta P$ that would be obtained by applying $\mathrm{ECCO}_{2} \mathrm{R}$ can theoretically be predicted according to the following relation, derived from the physiological equations defining alveolar ventilation [6]: of this analysis, we estimated that a sample size of 85 patients would yield $90 \%$ power to detect a correlation between predicted and observed changes in $\Delta P$ with $r \geq 0.4$ at a Type 1 error risk of $1 \%$. This sample size was also sufficient to estimate the Bland-Altman limits of agreement with confidence intervals of $\pm 0.1 \mathrm{cmH}_{2} \mathrm{O}$ assuming the standard deviation of the difference between predicted and observed changes in $\Delta P$ was $\leq 2 \mathrm{cmH}_{2} \mathrm{O}$.

Because lowering $V_{\mathrm{t}}$ may alter Crs by relieving hyperinflation (increasing Crs) or exacerbating atelectasis (worsening $\mathrm{Crs}$ ), the resulting change in $\Delta P$ may reflect both reductions in $V_{\mathrm{t}}$ and changes in Crs. Worsening compliance after lowering $V_{\mathrm{t}}$ would attenuate the effect of lowering $V_{\mathrm{t}}$ on $\Delta P$ and such changes in Crs might be prevented by increasing PEEP. To estimate the accuracy of predicting changes in $\Delta P$ with such a PEEP titration strategy, we compared the observed and predicted changes in $\Delta P$ using the baseline $\mathrm{Crs}$ value to compute $\triangle P$ before and after the application of $\mathrm{ECCO}_{2} \mathrm{R}$.

\section{Simulating potential clinical trials designed based on predicted treatment effect}

Sample size and screening size requirements were estimated for possible future $\mathrm{ECCO}_{2} \mathrm{R}$ trial designs with mortality as the primary endpoint. Trial designs employing different $\mathrm{CO}_{2}$ removal rates and varying degrees of predictive enrichment (restricting enrollment based on predicted $\Delta P$ response) were compared. For each trial design, the predicted change in $\Delta \mathrm{P}$ that would be obtained by $\mathrm{ECCO}_{2} \mathrm{R}$ at the planned $\mathrm{CO}_{2}$ removal rate was calculated for all patients in the SUPERNOVA study population based on Eq. 1. To account for possible

$$
\Delta P_{\mathrm{aw}, 2}-\Delta P_{\mathrm{aw}, 1}=\frac{-k}{C_{\mathrm{RS}} \cdot\left(1-V_{\mathrm{d}, \mathrm{alv}} / V_{\mathrm{t}}\right) \cdot \mathrm{RR} \times P_{\mathrm{aCO}_{2}}} \cdot \dot{V}_{\mathrm{CO}_{2}, \mathrm{ECML}}
$$

where $\mathrm{Crs}$ is the compliance of the respiratory system, $V_{\mathrm{d}, \text { alv }} / V_{\mathrm{t}}=\mathrm{ADF} ; \mathrm{RR}=$ respiratory rate (breaths $/ \mathrm{min}$ ); $\dot{V}_{\mathrm{CO}_{2}, \mathrm{ECML}}=\mathrm{CO}_{2}$ removal rate by the $\mathrm{ECCO}_{2} \mathrm{R}$ device $(\mathrm{ml} / \mathrm{min})$; and $k=0.863$. The predicted change in $\Delta P$ was computed for each patient using Eq. 1 . Because the actual $\mathrm{CO}_{2}$ clearance rate achieved in each patient was not measured in SUPERNOVA, we assessed the impact of three different possible values for average $\mathrm{CO}_{2}$ removal $(80 \mathrm{ml} / \mathrm{min}, 120 \mathrm{ml} / \mathrm{min}$, and $150 \mathrm{ml} / \mathrm{min})$.

The predicted and observed changes in $\Delta P$ obtained after applying $\mathrm{ECCO}_{2} \mathrm{R}$ were compared using linear regression, Bland-Altman analysis, and receiver operating characteristic curve (ROC) analysis. For the purpose error in the predicted change in $\Delta P$, random error $(95 \%$ $\left.\mathrm{CI} \pm 4 \mathrm{cmH}_{2} \mathrm{O}\right)$ was added to the predicted change in $\Delta P\left(4 \mathrm{cmH}_{2} \mathrm{O}\right.$ was chosen based on the limits of agreement for predicted and observed changes in $\Delta P$ ). Each trial design was simulated 500 times, and the median, 5th percentile, and 95th percentile values for the predicted change in $\Delta P$ were used to predict the absolute risk reduction in mortality (ARR). To compute ARR, we assumed that a $7 \mathrm{cmH}_{2} \mathrm{O}$ reduction in $\Delta P$ was associated with a hazard ratio for mortality (HR) of 0.68 as previously reported [11] and that $\mathrm{ECCO}_{2} \mathrm{R}$ carries a $1 \%$ increase in absolute risk of death due to treatment-related complications [5]. We further assumed a control group 
Table 1 Baseline clinical and physiological characteristics of the study population

\begin{tabular}{|c|c|c|c|c|}
\hline \multirow[t]{2}{*}{ Characteristic } & \multirow[t]{2}{*}{ Study population $(n=95)$} & \multicolumn{3}{|c|}{ Decrease in standardized $\Delta P$ with $\mathrm{ECCO}_{2} \mathrm{R}(n=87)$} \\
\hline & & $\leq 4 \mathrm{cmH}_{2} \mathrm{O}(n=41,47 \%)$ & $>4 \mathrm{~cm} \mathrm{H}_{2} \mathrm{O}(n=46,53 \%)$ & $p$-value \\
\hline Age (years) & $60.2(14)$ & $61.1(16)$ & $59.3(12.7)$ & 0.55 \\
\hline Sex $(n, \%$ female $)$ & $30(32 \%)$ & $12(29 \%)$ & $16(35 \%)$ & 0.75 \\
\hline SAPS $\|$ & $44(34-58)$ & $43(31-50)$ & $45(34-60)$ & 0.23 \\
\hline SOFA & $7(5-10)$ & $6(4-9)$ & $8(6-10)$ & 0.055 \\
\hline \multicolumn{5}{|l|}{ Cause of respiratory failure } \\
\hline Bacterial pneumonia & $65(68 \%)$ & $26(63 \%)$ & $31(67 \%)$ & 0.90 \\
\hline Viral pneumonia & $13(14 \%)$ & $7(17 \%)$ & $6(13 \%)$ & 0.90 \\
\hline Non-pulmonary sepsis & $3(3 \%)$ & $1(2 \%)$ & $2(4 \%)$ & 0.90 \\
\hline Other & $14(15 \%)$ & $7(17 \%)$ & $7(15 \%)$ & 0.90 \\
\hline $\mathrm{PaO}_{2} / \mathrm{FiO}_{2}(\mathrm{mmHg})$ & $153(121-178)$ & $160(136-174)$ & $143(119-182)$ & 0.42 \\
\hline Compliance $\left(\mathrm{ml} / \mathrm{cm} \mathrm{H}_{2} \mathrm{O}\right)$ & $31(24-38)$ & $32(26-39)$ & $28(20-35)$ & 0.008 \\
\hline Estimated alveolar dead space fraction & $0.32(0.22-0.37)$ & $0.28(0.21-0.35)$ & $0.33(0.26-0.41)$ & 0.016 \\
\hline Ventilatory ratio & $2.00(1.63-2.48)$ & $1.74(1.57-2.14)$ & $2.18(1.88-2.59)$ & 0.002 \\
\hline Minute ventilation (I/min) & $10.4(8.5-11.9)$ & $10.2(8.5-11.2)$ & $10.7(8.6-12.6)$ & 0.28 \\
\hline \multicolumn{5}{|l|}{ Tidal volume at baseline (ml/kg PBW) } \\
\hline Observed & $6.0(5.9-6.1)$ & $6.0(5.9-6.1)$ & $6.0(5.9-6.1)$ & 0.93 \\
\hline Standardized & $5.9(5.3-6.5)$ & $5.5(5.1-6.3)$ & $6.2(5.6-6.6)$ & 0.009 \\
\hline \multicolumn{5}{|c|}{ Tidal volume after applying $\mathrm{ECCO}_{2} \mathrm{R}(\mathrm{ml} / \mathrm{kg} \mathrm{PBW})$} \\
\hline Observed & $4.0(3.9-4.1)$ & $4.0(4.0-4.1)$ & $4.0(3.9-4.1)$ & 0.65 \\
\hline Standardized & $3.9(3.7-4.1)$ & $3.9(3.7-4.1)$ & $4.0(3.8-4.1)$ & 0.55 \\
\hline Respiratory rate $\left(\mathrm{min}^{-1}\right)$ & $28(24-30)$ & $27(22-30)$ & $28(25-31)$ & 0.25 \\
\hline Plateau pressure $\left(\mathrm{cm} \mathrm{H}_{2} \mathrm{O}\right)$ & $27(25-28)$ & $26(25-27)$ & $28(27-29)$ & $<0.001$ \\
\hline \multicolumn{5}{|l|}{ Driving pressure at baseline $\left(\mathrm{cm} \mathrm{H}_{2} \mathrm{O}\right)$} \\
\hline Observed & $13(10-15)$ & $12(10-13)$ & $14(11-18)$ & $<0.001$ \\
\hline Standardized & $12(10-15)$ & $10(9-13)$ & $13(12-18)$ & $<0.001$ \\
\hline \multicolumn{5}{|c|}{ Driving pressure after applying $\mathrm{ECCO}_{2} \mathrm{R}\left(\mathrm{cmH}_{2} \mathrm{O}\right)$} \\
\hline Observed & $9(6-11)$ & $9(7-11)$ & $9(6-12)$ & 0.95 \\
\hline Standardized & $8(6-11)$ & $8(7-11)$ & $8(6-11)$ & 0.99 \\
\hline \multicolumn{5}{|l|}{$\mathrm{ECCO}_{2} \mathrm{R}$ device type } \\
\hline Lower $\mathrm{CO}_{2}$ extraction & $33(35 \%)$ & $19(46 \%)$ & $12(26 \%)$ & 0.08 \\
\hline Higher $\mathrm{CO}_{2}$ extraction & $62(65 \%)$ & $22(54 \%)$ & $34(74 \%)$ & 0.08 \\
\hline $\operatorname{PEEP}\left(\mathrm{cmH}_{2} \mathrm{O}\right)$ & $14(10-16)$ & $15(12-16)$ & $12(10-16)$ & 0.12 \\
\hline $\mathrm{FiO}_{2}$ & $60(50-70)$ & $60(50-70)$ & $60(50-70)$ & 0.62 \\
\hline $\mathrm{pH}$ & $7.34(7.3-7.4)$ & $7.34(7.29-7.40)$ & $7.34(7.30-7.39)$ & 0.84 \\
\hline $\mathrm{PaCO}_{2}(\mathrm{~mm} \mathrm{Hg})$ & $45(41-55)$ & $43(39-48)$ & $50(43-56)$ & 0.011 \\
\hline Bicarbonate (mmol $\mathrm{L}^{-1}$ ) & $25(22-28)$ & $23(22-25)$ & $26(23-30)$ & 0.019 \\
\hline Base excess $\left(\mathrm{mmol} \mathrm{L}^{-1}\right)$ & $0(-3-2)$ & $-2(-5-1)$ & $1(-2-4)$ & 0.026 \\
\hline
\end{tabular}

$\triangle P$, airway driving pressure; $\mathrm{ECCO}_{2} \mathrm{R}$, extracorporeal $\mathrm{CO}_{2}$ removal; SAPS II, severe acute physiology score; SOFA, sequential organ failure assessment; $\mathrm{PBW}$, predicted body weight; PEEP, positive end-expiratory pressure

mortality rate based on the mortality rates observed for each subgroup of predicted responders in SUPERNOVA. Sample size estimates were computed from predicted ARR values assuming a 5\% risk of Type I error and a $20 \%$ risk of Type II error. In a sensitivity analysis, ARR and sample size were re-estimated using an HR of 0.75 (based on the treatment effect observed in a previous trial of lung-protective ventilation) [6] instead of 0.68 . The number of serious adverse events in patients randomized to $\mathrm{ECCO}_{2} \mathrm{R}$ was predicted based on the rate observed in SUPERNOVA (6/95, 6\%).

All analyses were conducted using $\mathrm{R}$ version 3.5.1 (http://www.r-project.org). 


\section{Results}

\section{Patient physiological characteristics and responses} to $\mathrm{ECCO}_{2} \mathrm{R}$

Patient clinical and physiological characteristics are shown in Table 1 . Due to missing data in plateau pressure measurements $(n=4), \mathrm{PaCO}_{2}(n=1)$, and computed alveolar dead space fraction $(n=2)$, and because sweep gas flow was not applied in 1 patient, the changes in standardized $V_{\mathrm{t}}$ and $\Delta P$ could be computed in 87 patients. The median time between baseline and post$\mathrm{ECCO}_{2} \mathrm{R}$ measurements was $150 \mathrm{~min}$ (IQR 80-300 min). $\mathrm{ECCO}_{2} \mathrm{R}$ was applied using a higher $\mathrm{CO}_{2}$ extraction device in 62 patients $(65 \%)$ and a lower $\mathrm{CO}_{2}$ extraction device in 33 patients (35\%).

The change in standardized $V_{\mathrm{t}}$ after applying $\mathrm{ECCO}_{2} \mathrm{R}$ varied widely among patients (Figure E1, median $-2.0 \mathrm{ml} / \mathrm{kg}$, range -1.1 to $-4.0 \mathrm{ml} / \mathrm{kg}$ ). The change in standardized $\triangle P$ after applying $\mathrm{ECCO}_{2} \mathrm{R}$ also varied widely (Figure $\mathrm{E} 1$, median $-4.1 \mathrm{cmH}_{2} \mathrm{O}$, range -11.1 to $1.7 \mathrm{cmH}_{2} \mathrm{O}$ ), partly because of large changes in Crs in some patients (Figure E1, Crs increased or decreased by more than $5 \mathrm{ml} / \mathrm{cmH}_{2} \mathrm{O}$ in $35 \%$ of patients). The change in standardized Power $_{R S}$ also varied widely (Figure E1, median $-3.8 \mathrm{~J} / \mathrm{min}$, range -8.7 to $0.3 \mathrm{~J} / \mathrm{min}$ ).
At $8 \mathrm{~h}$ from $\mathrm{ECCO}_{2} \mathrm{R}$ initiation, 74 patients (78\%) achieved the primary end-point: 18 of 33 patients (55\%) on the lower $\mathrm{CO}_{2}$ extraction device and 56 of 62 patients (90\%) on the higher $\mathrm{CO}_{2}$ extraction devices $(p<0.001)$.

Demographics, cause of ARDS, baseline $\mathrm{PaO}_{2} / \mathrm{FiO}_{2}$, and severity of illness were similar among patients with smaller ( $>$ median of $\left.-4 \mathrm{cmH}_{2} \mathrm{O}\right)$ vs. larger $(\leq$ median of $\left.-4 \mathrm{cmH}_{2} \mathrm{O}\right)$ changes in standardized $\Delta P$ after applying $\mathrm{ECCO}_{2} \mathrm{R}$ (Table 1). Baseline $\Delta P$, plateau pressure, $\mathrm{VR}$, and $\mathrm{PaCO}_{2}$ were significantly higher in patients with a larger reduction in standardized $\Delta P$ with $\mathrm{ECCO}_{2} \mathrm{R}$, reflecting lower Crs and higher ADF (Table 1).

\section{Determinants of effect of $\mathrm{ECCO}_{2} \mathrm{R}$ on tidal volume, driving pressure, and mechanical power}

In bivariate linear regression, the change in standardized $V_{\mathrm{t}}$ after applying $\mathrm{ECCO}_{2} \mathrm{R}$ was associated with ADF, VR, and device performance, but not with $\mathrm{Crs}$ or $\mathrm{PaO}_{2} / \mathrm{FiO}_{2}$ (Fig. 1); similar findings were obtained in multivariable regression incorporating all these variables (Table E1).

The change in standardized $\Delta P$ after the application of $\mathrm{ECCO}_{2} \mathrm{R}$ was associated with $\mathrm{ADF}, \mathrm{VR}, \mathrm{Crs}$, and $\mathrm{PaO}_{2} /$ $\mathrm{FiO}_{2}$ (Fig. 2); in multivariable analysis incorporating all these variables, the effect of $\mathrm{PaO}_{2} / \mathrm{FiO}_{2}$ was no longer significant (Table E1).

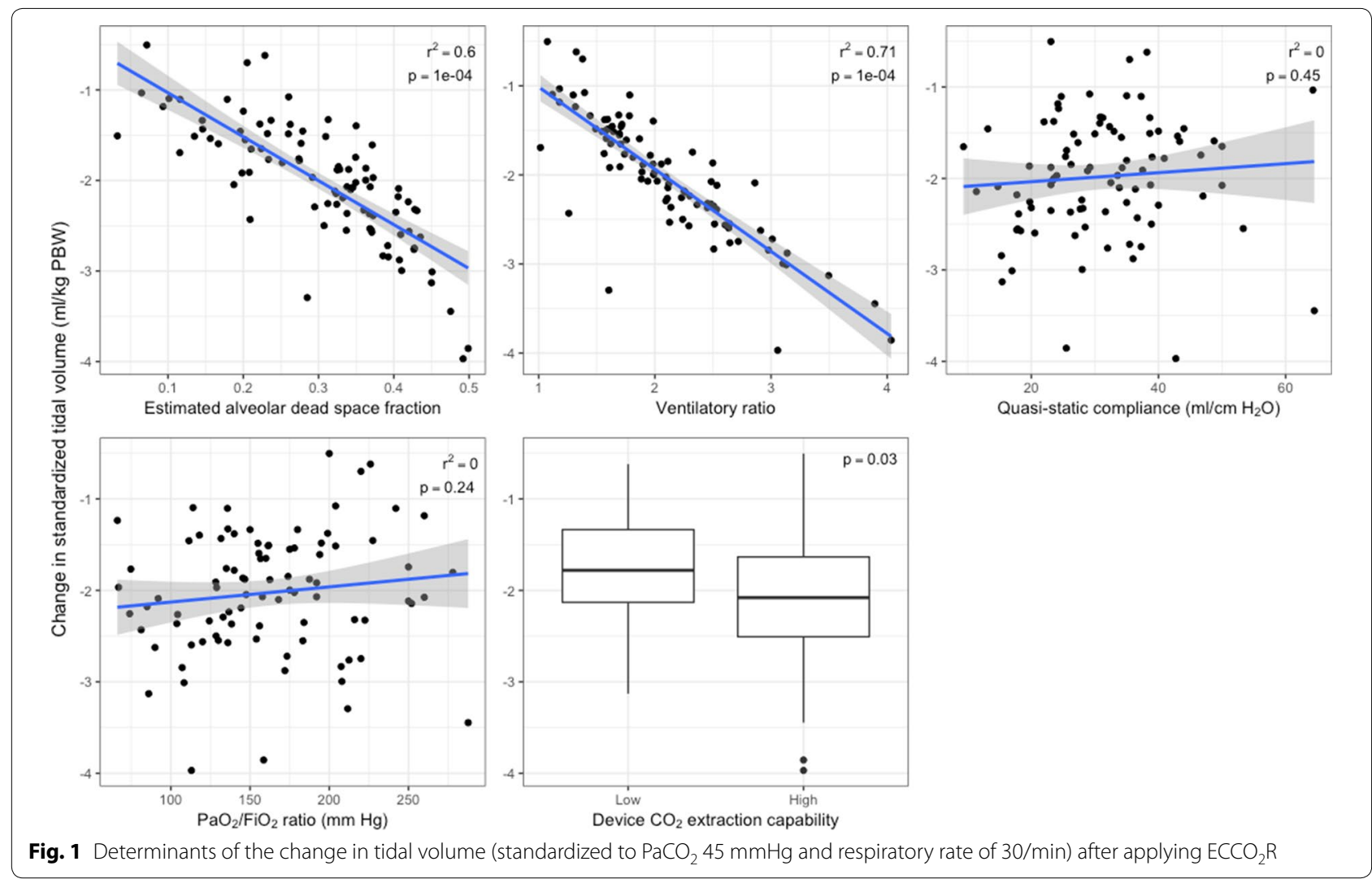




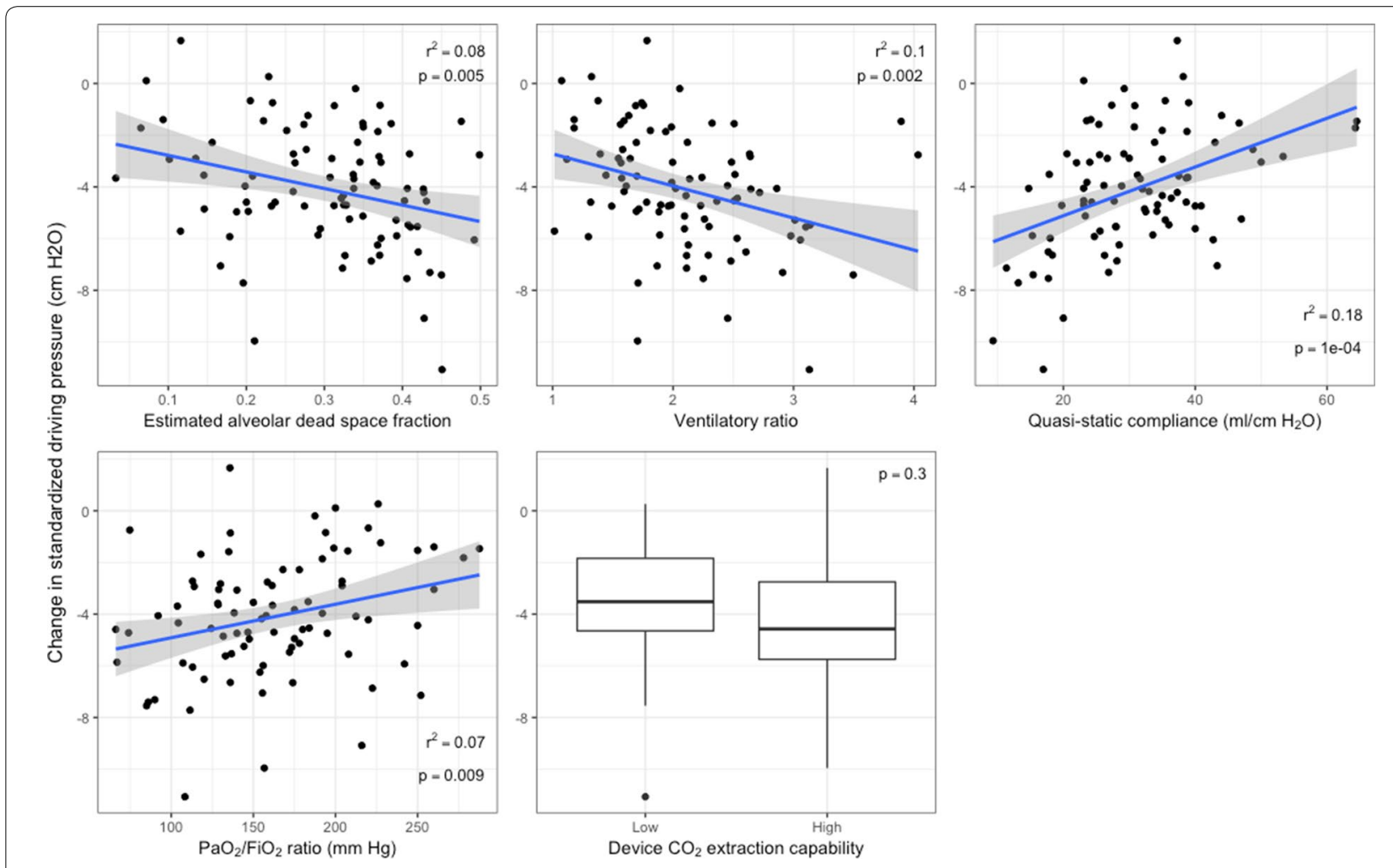

Fig. 2 Determinants of the change in driving pressure (standardized to $\mathrm{PaCO}_{2} 45 \mathrm{mmHg}$ and respiratory rate of $30 / \mathrm{min}$ ) after applying $\mathrm{ECCO}_{2} \mathrm{R}$. After adjusting for alveolar dead space fraction and compliance, the effect of $\mathrm{PaO}_{2} / \mathrm{FiO}_{2}$ was no longer significant

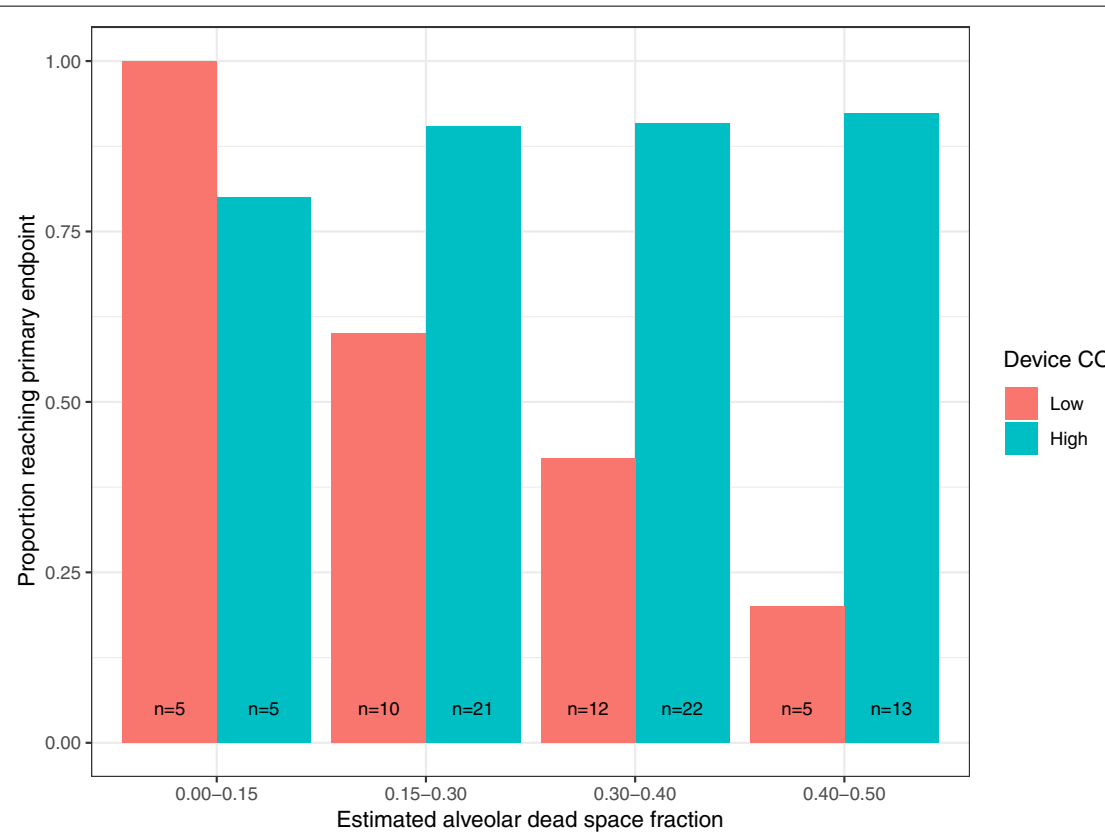

Fig. 3 Alveolar dead space fraction determines the degree of $\mathrm{CO}_{2}$ removal required to achieve the primary endpoint in the SUPERNOVA trial (tidal volume $\leq 4 \mathrm{ml} / \mathrm{kg}$ PBW and $\mathrm{pH} \geq 7.3$ and $\mathrm{PaCO}_{2}$ within $20 \%$ of baseline) at $8 \mathrm{~h}$ after initiation of $\mathrm{ECCO}_{2} \mathrm{R}(p=0.03$ for interaction). At lower alveolar dead space fraction, reductions in $V_{t}$ from 6 to $4 \mathrm{ml} / \mathrm{kg}$ can be achieved with relatively less extracorporeal $\mathrm{CO}_{2}$ removal whereas patients with higher alveolar dead space fraction require higher $\mathrm{CO}_{2}$ removal to reduce $V_{\mathrm{t}}$. The number of patients in each group is shown within the bar 
The change in standardized Power $_{\mathrm{RS}}$ after the application of $\mathrm{ECCO}_{2} \mathrm{R}$ was associated with $\mathrm{ADF}, \mathrm{VR}, \mathrm{Crs}$, $\mathrm{PaO}_{2} / \mathrm{FiO}_{2}$, and device performance (Figure E2); in multivariable analysis incorporating all these variables, the effect of $\mathrm{PaO}_{2} / \mathrm{FiO}_{2}$ was no longer significant (Table E1).

The combined effects of $\mathrm{Crs}$ and $\mathrm{ADF}$ on the change in standardized $\Delta P$ and standardized Power $_{\mathrm{RS}}$ are represented in Figure E3.

The probability of reaching the SUPERNOVA trial primary end-point was higher when $\mathrm{ECCO}_{2} \mathrm{R}$ was applied using a higher $\mathrm{CO}_{2}$ extraction device (Figure E4), particularly in patients with higher ADF (Fig. 3, $p=0.03$ for interaction). This interaction with ADF persisted in multivariable analysis (Table E1). All patients on lower $\mathrm{CO}_{2}$ extraction devices required maximum sweep gas flow to achieve the study endpoint, whereas in patients on higher $\mathrm{CO}_{2}$ extraction devices, the sweep gas flow required to achieve the study endpoint progressively increased with increasing ADF (Figure E5).

\section{Predicting the effect of $\mathrm{ECCO}_{2} \mathrm{R}$ on driving pressure}

The observed change in standardized $\Delta \mathrm{P}$ was correlated with the predicted change in driving pressure $\left(R^{2}=0.32\right.$, $p<0.001$, Figure E6). In Bland-Altman analysis, predicted and observed changes in $\Delta P$ differed by up to $\pm 3.9 \mathrm{cmH}_{2} \mathrm{O}$ (Figure E6, Table E2); the bias varied with

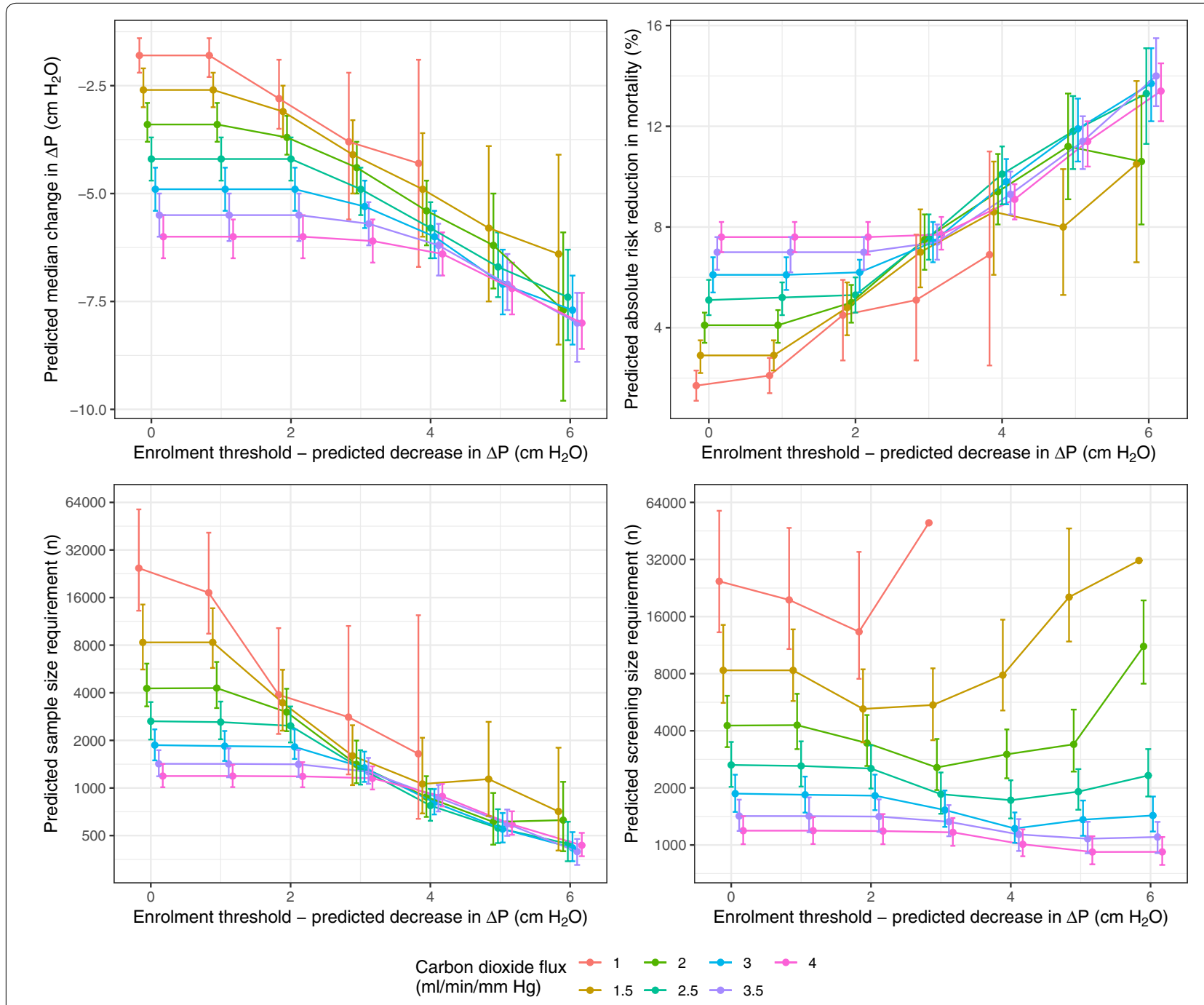

Fig. 4 Predicted effect of $\mathrm{ECCO}_{2} \mathrm{R}$ on $\triangle P$ (top left panel) and mortality risk (top right panel) in trial designs using different enrollment criteria and different degrees of device performance $\left(\mathrm{CO}_{2}\right.$ removal). The error bars represent the 5 th and 95 th percentile values for the median change in $\triangle P$ predicted after incorporating random prediction error of $\pm 4 \mathrm{cmH}_{2} \mathrm{O}$. The predicted effect on mortality was used to compute sample size requirement (bottom left panel). Because only a subset of patients meet the threshold for inclusion, the number of otherwise eligible ARDS patients who need to be identified by screening (bottom right panel) is higher than the sample size for randomization 
the assumed rate of $\mathrm{CO}_{2}$ removal used to predict the change in $\Delta P$ (Table E2). Discrimination between higher and lower responders was moderately acceptable (area under receiver operating characteristic curve 0.72, Figure E6).

After recomputing the predicted change in $\Delta P$ using the same value for Crs at both baseline and at $4 \mathrm{ml} / \mathrm{kg}$ to evaluate predictive performance under conditions of stable Crs (e.g. to simulate the effect of titrating PEEP to prevent decreases in Crs resulting from $\mathrm{ECCO}_{2} \mathrm{R}$-facilitated reductions in $V_{\mathrm{t}}$ ), the correlation between predicted and observed values was considerably higher $\left(R^{2}=0.74\right)$, limits of agreement were narrower $\left( \pm 2.1 \mathrm{cmH}_{2} \mathrm{O}\right)$, and predictive discrimination improved substantially (area under receiver operating characteristic curve 0.92) (Table E2).

\section{Trial design simulations}

Figure 4 provides predicted sample size requirements computed in $\mathrm{ECCO}_{2} \mathrm{R}$ trial simulations using different values of predicted change in $\Delta P$ to define eligibility for enrolment. Results at predicted change in $\Delta P=0$ represent the sample sizes required in the absence of predictive enrichment. Greater $\mathrm{CO}_{2}$ removal and restricting enrollment to patients with a higher predicted $\Delta P$ response reduced predicted sample size requirements (Fig. 4). The effect of restricting enrollment to patients with a greater predicted reduction in $\Delta P$ on sample size requirements (Fig. 4) and hence on serious adverse event rates (Figure E7) was greatest at lower $\mathrm{CO}_{2}$ removal rates.

Based on these calculations, a trial designed applying $\mathrm{ECCO}_{2} \mathrm{R}$ of at least $3 \mathrm{ml} / \mathrm{min} / \mathrm{mmHg}$ (approximately $135 \mathrm{ml} / \mathrm{min}$ assuming an average $\mathrm{PaCO}_{2}$ of $45 \mathrm{mmHg}$ ) to patients like those in SUPERNOVA and using a predicted reduction in $\Delta P \geq 5 \mathrm{cmH}_{2} \mathrm{O}$ to determine eligibility for randomization would need to identify 1340 otherwise eligible patients with ARDS, of whom 548 (41\%) would meet enrollment criteria and be randomized to refute a predicted $12 \%$ absolute risk reduction in mortality. In a sensitivity analysis employing a less optimistic mortality effect (HR 0.75), the same trial design would need to identify 2460 eligible patients, of whom 1006 would meet enrollment criteria and be randomized (see Supplemental Tables and Online Supplement for details).

An online calculator to predict treatment response in individual patients has been made available at https://bit. ly/2RRHevj.

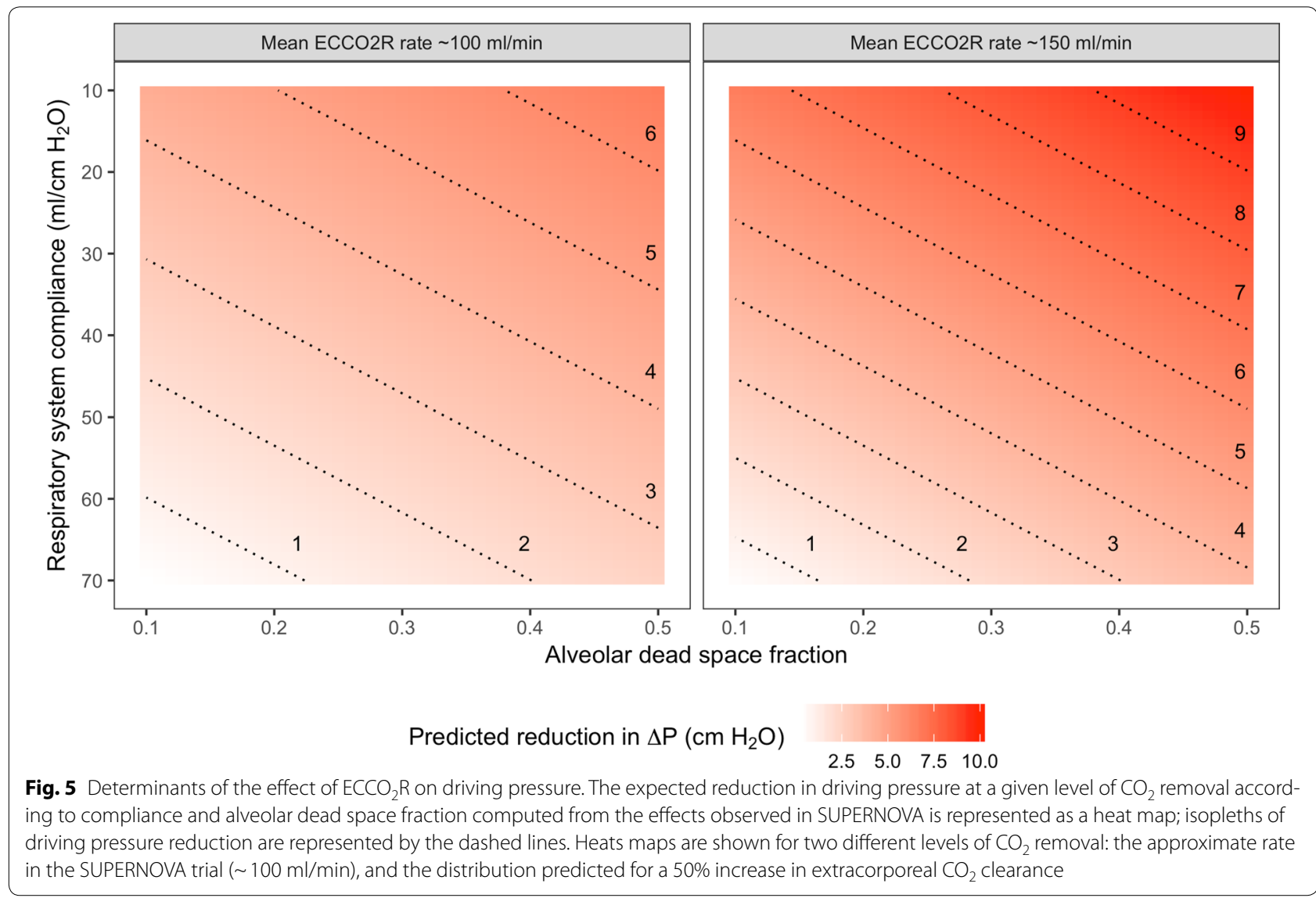




\section{Discussion}

This study demonstrates that the effect of $\mathrm{ECCO}_{2} \mathrm{R}$ on $V_{\mathrm{t}}$, $\triangle P$, and Power $_{\mathrm{RS}}$ varies widely in patients with moderate ARDS as substantially determined by ADF, Crs, and the $\mathrm{CO}_{2}$ extraction capability of the $\mathrm{ECCO}_{2} \mathrm{R}$ device. These findings suggest that patients with higher ADF or lower Crs and patients treated with higher $\mathrm{CO}_{2}$ extraction are most likely to benefit from $\mathrm{ECCO}_{2} \mathrm{R}$ (Fig. 5 and Figure $\mathrm{E} 8$ ). We also found that the a priori model for predicting the change in $\triangle P$ obtained by $\mathrm{ECCO}_{2} \mathrm{R}$ was only moderately accurate, possibly because a number of key variables (e.g. actual $\mathrm{CO}_{2}$ removal rate) were not measured in the SUPERNOVA trial and because of changes in Crs after applying $\mathrm{ECCO}_{2} \mathrm{R}$ and reducing $V_{\mathrm{t}}$. Finally, simulations of treatment effect in different trial designs contingent upon a range of assumptions (discussed below) suggest that a future trial of $\mathrm{ECCO}_{2} \mathrm{R}$-facilitated ultra-protective ventilation powered to detect impact on clinical outcomes, incorporating both predictive enrichment and enhanced $\mathrm{CO}_{2}$ clearance, is feasible.

Even in an age of 'big data', the randomized clinical trial remains the most powerful and reliable tool to test new therapies in clinical practice. However, the many 'negative' trials in critical care have spurred important innovations in trial design $[12,13]$. Predictive enrichment is one approach to enhance the probability of demonstrating benefit (if any) by selecting patients most likely to respond. The importance of enrichment in the case of $\mathrm{ECCO}_{2} \mathrm{R}$ is highlighted by the widely varying effect of $\mathrm{ECCO}_{2} \mathrm{R}$ on $\triangle P$ observed in this study and the known risk of treatment-related complications.

A theoretical analysis of the physiological equations defining alveolar ventilation suggested that the effect of $\mathrm{ECCO}_{2} \mathrm{R}$ on $\triangle P$ would be positively correlated to ADF and inversely related to Crs [6]. ADF determines the magnitude and frequency of tidal inflation required for pulmonary ventilation, while Crs determines the pressure required to achieve this tidal inflation. Accordingly, reducing the requirement for pulmonary ventilation by $\mathrm{ECCO}_{2} \mathrm{R}$ will reduce the requirement for tidal volume and pressure in proportion to ADF and Crs. This study confirms this hypothesis. Although we did not directly measure ADF, empirical estimates of ADF were strongly correlated with changes in $V_{\mathrm{t}}, \Delta P$, and Power $_{\mathrm{RS}}$, and this finding was corroborated by observing similar effects with VR (a surrogate marker for physiological dead space) [8]. The effect of $\mathrm{ECCO}_{2} \mathrm{R}$ on $\Delta P$ and Power $_{\mathrm{RS}}$ was correlated with baseline respiratory compliance as expected, given the mathematical and physiological coupling between these variables. Importantly, although baseline $\mathrm{PaO}_{2} / \mathrm{FiO}_{2}$ ranged between 92 and $242 \mathrm{mmHg}$ in SUPERNOVA, the effect of $\mathrm{ECCO}_{2} \mathrm{R}$ on $\Delta P$ was unrelated to the severity of hypoxemia (the usual measure of ARDS severity) after adjusting for ADF and Crs. This suggests that ADF and Crs, rather than severity of hypoxemia, should be the primary factors in determining whether to enroll patients in clinical trials of $\mathrm{ECCO}_{2} \mathrm{R}$.

The success of predictive enrichment is contingent upon two conditions: (a) the availability of a predictive 'biomarker' that reliably reflects the causal mechanism conditioning outcome [14]; and (b) reliable and feasible detection or prediction of the biomarker response. The predictive validity ('credentials') of various biomarkers of ventilator-induced lung injury remains the subject of considerable debate: options include $V_{\mathrm{t}}, \Delta P$, and Power $_{\mathrm{RS}}$. There is evidence that both the magnitude and frequency of tidal ventilation contribute to lung injury as reflected by Power $_{\mathrm{RS}}$ [15]-ECCO $\mathrm{R}$ could permit both tidal volume and respiratory frequency to be lowered, leading to substantial reductions in Power $_{\mathrm{RS}}$. Our trial design simulation analysis focused on driving pressure given the body of evidence in its favor and data linking $\Delta P$ with mortality $[2,11]$.

Even if a biomarker with acceptable credentials is available, the effect of treatment on that biomarker must be reliably determined before randomization. While a 'test dose' of some therapies could be used to assess biomarker response (e.g. the gas exchange response to higher PEEP in mechanical ventilation) [16], a 'test dose' of $\mathrm{ECCO}_{2} \mathrm{R}$ cannot be applied because it is invasive, costly, and associated with potentially serious adverse events. Predicting the response to $\mathrm{ECCO}_{2} \mathrm{R}$ is therefore crucial to incorporating predictive enrichment in the design of trials evaluating $\mathrm{ECCO}_{2} \mathrm{R}$-facilitated ultra-protective ventilation.

Despite a sound theoretical basis and confirmatory associations between treatment effect and both ADF and Crs, a previously derived model based on these parameters was only moderately successful in predicting the $\mathrm{ECCO}_{2} \mathrm{R}$ response in this study. Limits of agreement between predicted and observed changes in $\Delta P$ were wide and the ability to discriminate between patients with or without a significant treatment response (arbitrarily defined based on the median change in $\Delta P$ ) was limited. Several factors likely account for this. First, ADF was not measured, but was estimated empirically-a future trial could easily incorporate direct estimates of ADF based on end-tidal $\mathrm{CO}_{2}$ measurements. Second, $\mathrm{Crs}$ changed before and after $\mathrm{ECCO}_{2} \mathrm{R}$ application in many patients, possibly because lowering tidal volume relieved hyperdistention (compliance increased by $5 \mathrm{ml} / \mathrm{cmH}_{2} \mathrm{O}$ or more in $16 \%$ of patients) or caused alveolar derecruitment (compliance decreased by $5 \mathrm{ml} / \mathrm{cmH}_{2} \mathrm{O}$ or more in $19 \%$ of patients). Using a constant value for Crs substantially improved predictive discrimination. A future trial could incorporate a physiological strategy that aims to maintain [17] or even improve [18] Crs to maximize 
predictive accuracy and also to minimize $\Delta P$ as part of its interventional approach.

Third, accurate prediction of device performance $\left(\mathrm{CO}_{2}\right.$ removal) is crucial for accurate predictions of patient response. $\mathrm{CO}_{2}$ removal rates were not directly measured in SUPERNOVA, but predicted device $\mathrm{CO}_{2}$ extraction strongly modified the ability to achieve ultra-protective ventilation targets, particularly in patients with higher ADF. In patients with lower ADF, considerable reductions in $V_{\mathrm{t}}$ can be achieved while applying little or no $\mathrm{CO}_{2}$ removal (as indicated by the relatively low sweep gas flow requirements in these patients, Figure E4), whereas patients with higher ADF can attain only small decreases in $V_{\mathrm{t}}$ apart from $\mathrm{CO}_{2}$ removal (illustrated in Figure E6). Given the importance of device performance, particularly in patients with high ADF, device performance (i.e. $\mathrm{CO}_{2}$ removal) must be accurately predicted when deciding whether to apply $\mathrm{ECCO}_{2} \mathrm{R}$. $\mathrm{CO}_{2}$ elimination rates by membrane lungs are a complex function of several factors including sweep gas flow rate, membrane area, extracorporeal blood flow rate, venous $\mathrm{CO}_{2}$ tension, and membrane materials and design. The respective contributions of each of these variables are well understood from a biophysical perspective [10] and $\mathrm{CO}_{2}$ removal should in theory be highly predictable. Future studies should focus on developing and validating reliable models to predict $\mathrm{CO}_{2}$ removal under specified device settings for each of the devices on the market.

Despite the imperfect reliability of predicted treatment response, we show that predicting treatment effect would nevertheless substantially reduce sample size requirements, as suggested by the trial simulation results. Even when incorporating a random error in the predicted change in $\Delta P$ consistent with the limits of agreement between predicted and observed effects obtained in this study, simulated median changes in $\Delta P$ were substantially higher in predicted responders.

The estimated decrease in mortality using $\mathrm{ECCO}_{2} \mathrm{R}$ was computed from the predicted decrease in $\triangle P$ based on two crucial assumptions. First, the computation assumes that the association between $\Delta P$ and mortality reported in a previous mediation analysis is entirely causal [11]. In a sensitivity analysis, the use of a less optimistic hazard ratio for treatment effect on mortality increased sample size requirements. Second, this analysis assumes that the effect of reducing $\Delta P$ on mortality is independent of the baseline $\Delta P$ (i.e. there is no threshold effect). The benefit of reducing driving pressure even when plateau pressure is not elevated has been suggested in secondary analyses of clinical trials $[11,19]$ but remains unconfirmed. These assumptions are considered and discussed in detail elsewhere [6]. A future clinical trial is required to address these uncertainties. Assumptions about treatment effect are unavoidable in trial design, particularly in sample size computations. Adaptive designs can help to mitigate such assumptions by permitting ongoing enrollment if the treatment effect is weaker than expected [20]. An adaptive design might also initially employ broad inclusion criteria and adopt increasingly restrictive criteria if evidence accumulates that predicted responders experience greater benefit than predicted non-responders.

The main limitation of this analysis, aside from those reviewed above, is that the SUPERNOVA study was planned and carried out before the theoretical analysis linking changes in $\triangle P$ obtained with $\mathrm{ECCO}_{2} \mathrm{R}$ to individual patient physiological characteristics was published. For this reason, the measurements and procedures required to optimize predictive accuracy were not performed and adjustments were required to address confounding factors (i.e. concomitant changes in respiratory rate and $\mathrm{PaCO}_{2}$ target). A future $\mathrm{ECCO}_{2} \mathrm{R}$ trial designed to maximize the reduction in $\triangle P$ obtained from $\mathrm{ECCO}_{2} \mathrm{R}$ could address these limitations by directly measuring all relevant baseline variables prospectively (ADF, Crs, $\mathrm{CO}_{2}$ elimination) and computing the predicted change in $\Delta P$ prior to initiation of $\mathrm{ECCO}_{2} \mathrm{R}$.

\section{Conclusions}

The effect of $\mathrm{ECCO}_{2} \mathrm{R}$ on $V_{\mathrm{t}}, \Delta P$, and Power $_{\mathrm{RS}}$ varies widely in patients with moderate ARDS as substantially determined by ADF and Crs. These findings suggest that patients with higher ADF or lower Crs and patients treated with higher $\mathrm{CO}_{2}$ extraction devices are most likely to benefit from $\mathrm{ECCO}_{2} \mathrm{R}$ (Fig. 5). Incorporating predicted treatment response and higher $\mathrm{CO}_{2}$ removal rates as factors in trial design might substantially reduce screening and sample size requirements in a future trial of $\mathrm{ECCO}_{2} \mathrm{R}$-facilitated ultra-protective ventilation.

\section{Electronic supplementary material}

The online version of this article (https://doi.org/10.1007/s00134-019-05708-9) contains supplementary material, which is available to authorized users.

\footnotetext{
Author details

${ }^{1}$ Interdepartmental Division of Critical Care Medicine, University of Toronto, Toronto, Canada. ${ }^{2}$ Department of Medicine, Division of Respirology, University Health Network, Toronto, Canada. ${ }^{3}$ Toronto General Hospital Research Institute, 585 University Ave., 11-PMB Room 192, Toronto, ON M5G 2N2, Canada. ${ }^{4}$ APHP Hôpital Pitié-Salpêtrière, Institut de Cardiologie, Institute of Cardio-metabolism and Nutrition, and Service de Médecine Intensive-réanimation, UMRS_1166-ICAN, INSERM, Sorbonne Université, Paris, France. ${ }^{5}$ Division of Pulmonary, Allergy, and Critical Care Medicine, Columbia University College of Physicians and Surgeons, New York, NY, USA. ${ }^{6}$ Center for Acute Respiratory Failure, New York-Presbyterian Hospital, New York, NY, USA. ${ }^{7}$ Institute for Health Policy, Management, and Evaluation, University of Toronto, Toronto, Canada. ${ }^{8}$ Department of Physiology, University of Toronto, Toronto, Canada. ${ }^{9}$ Dipartimento di Anestesia, Rianimazione ed Emergenza Urgenza, Fondazione IRCCS Ca'Granda-Ospedale Maggiore Policlinico, Milan, Italy. ${ }^{10}$ Dipartimento di Fisiopatologia Medico-Chirurgica e dei Trapianti, Università degli Studi di Milano, Milan, Italy. ${ }^{11}$ Policlinico di Sant'Orsola, Anesthesia and Intensive Care Medicine, Dipartimento di Scienze Mediche
} 
e Chirurgiche, Alma Mater Studiorum-Università di Bologna, Bologna, Italy.

${ }^{12}$ Keenan Centre for Biomedical Research, Li Ka Shing Knowledge Institute, St. Michael's Hospital, Toronto, Canada.

\section{Acknowledgements}

Richard BEALE ${ }^{8}$, Laurent BROCHARD ${ }^{1,7}$, Jean-Daniel $C \mathrm{CHCHE}^{9}$, Eddy FAN ${ }^{1,2,3,5}$, Daniel DE BACKER ${ }^{10}$, Guy FRANCOIS ${ }^{11}$, John LAFFEY ${ }^{12}$, Alain MERCAT ${ }^{13}$, Daniel F. MCAULEY ${ }^{14}$, Thomas MÜLLER ${ }^{15}$, Michael QUINTEL ${ }^{16}$, Jean-Louis VINCENT ${ }^{17}$, Fabio Silvio TACCONE ${ }^{17}$, Harlinde PEPERSTRAETE ${ }^{18}$, Philippe MORIMONT ${ }^{19}$, Matthieu SCHMIDT ${ }^{4}$, Bruno LEVY ${ }^{20}$, Jean-Luc DIEHL ${ }^{21}$, Christophe GUERVILLY ${ }^{22}$, Gilles CAPELIER ${ }^{23}$, Antoine VIEILLARD-BARON ${ }^{24}$, Jonathan MESSIKA ${ }^{25}$, Christian KARAGIANNIDIS ${ }^{26}$, Onnen MOERER ${ }^{16}$, Rosario Urbino ${ }^{27}$, Massimo ANTONELLI ${ }^{28}$, Francesco MOJOLI ${ }^{29}$, Francesco ALESSANDRI ${ }^{30}$, Giacomo GRASSELLI ${ }^{6}$, Dirk DONKER ${ }^{31}$, Ricard FERRER ${ }^{32}$, Jordi MANCEBO ${ }^{33}$, Vito FANELLI ${ }^{27}$, Tai PHAM ${ }^{7}$

${ }^{1}$ Interdepartmental Division of Critical Care Medicine, University of Toronto, Toronto, Canada; ${ }^{2}$ Department of Medicine, Division of Respirology, University Health Network, Toronto, Canada; ${ }^{3}$ Toronto General Hospital Research Institute, Toronto, Canada; ${ }^{4}$ Sorbonne Université, INSERM, UMRS_1166-ICAN, Institute of Cardio-metabolism and Nutrition, and Service de médecine intensive-réanimation, Institut de Cardiologie, APHP Hôpital Pitié-Salpêtrière, PARIS, France; ${ }^{5}$ Institute for Health Policy, Management, and Evaluation, University of Toronto, Toronto, Canada; ${ }^{6}$ Dipartimento di Anestesia, Rianimazione ed Emergenza Urgenza, Fondazione IRCCS Ca' Granda-Ospedale Maggiore Policlinico, Milan, Italy: ${ }^{7}$ Keenan Centre for Biomedical Research, Li Ka Shing Knowledge Institute, St. Michael's Hospital, Toronto, Canada; ${ }^{8}$ Guy's and St. Thomas' NHS Foundation Trust, London, UK; ${ }^{9}$ Hôpital Cochin, Université Paris Descartes, France; ${ }^{10}$ Hôpital de Braine l'Alleud-Waterloo, Université Libre de Bruxelles, Belgium; ${ }^{11}$ European Society of Intensive Care Medicine, Brussels, Belgium; ${ }^{12}$ Galway University Hospitals, Galway, Ireland; ${ }^{13} \mathrm{Centre}$ Hospitalier Universitaire, University of Angers, France; ${ }^{14}$ Centre for Experimental Medicine, Queen's University Belfast and Regional Intensive Care Unit, Royal Victoria Hospital, Belfast, UK; ${ }^{15}$ University Hospital Regensburg, Regensburg, Germany; ${ }^{16}$ Universitätsmedizin Göttingen, Germany; ${ }^{17}$ Erasme Hospital, Brussels Free University, Belgium; ${ }^{18}$ Ghent University Hospital, Belgium; ${ }^{19}$ University Hospital Liège, Belgium; ${ }^{20}$ Service de Réanimation Médicale Brabois, CHRU Nancy, Pôle Cardio-Médico-Chirurgical, INSERM U1116, Faculté de Médecine, 54511 Vandoeuvre-les-Nancy, France ; Université de Lorraine, Nancy, France; ${ }^{21}$ Hôpital Européen Georges Pompidou, Paris, France; ${ }^{22}$ AP-HM Hôpital Nord, Marseille, France; ${ }^{23}$ Centre Hospitalier Universitaire de Besançon, France; ${ }^{24} \mathrm{Hôpital}$ Ambroise Paré, Paris, France; ${ }^{25}$ Hôpital Louis Mourier, Paris, France; ${ }^{26}$ Kliniken der Stadt, Köln, Germany; ${ }^{27}$ University of Turin, Città della Salute e della Scienza di Torino, Department of Anesthesia and Intensive Care Medicine, Turin, Italy; ${ }^{28}$ Università Cattolica-Policlinico Universitario A.Gemelli, Roma, Italy; ${ }^{29}$ Fondazione IRCCS Policlinico San Matteo, Pavia, Italy; ${ }^{30}$ Policlinico Umberto I, Roma, Italy; ${ }^{31}$ University Medical Center, Utrecht University Medical Center, Utrecht, Netherlands; ${ }^{32}$ Hospital Universitari Vall d'Hebron, Barcelona, Spain; ${ }^{33}$ Hospital de la Santa Creu i Sant Pau, Barcelona, Spain

\section{Author contributions}

EG and AS conceived the study. EG, AC, DB, VMR, and AS designed the study. $A C, D B, N D F, V M R$, and AS acquired the study measurements. EG conducted the analysis. All authors contributed to the interpretation of the findings. EG and AS drafted the manuscript and all authors critically revised the manuscript for intellectually important content. All authors gave final approval for the publication of the work and all accepted responsibility for the integrity of the work.

\section{Sources of funding}

Dr. Goligher is supported by an Early Career Investigator Award (AR7-162822) from the Canadian Institutes of Health Research and an IDCCM scholarship from the University of Toronto. Dr. Slutsky is supported in part by grants 137772 and 143285 from the Canadian Institutes of Health Research.

\section{Compliance with ethical standards}

\section{Conflicts of interest}

Dr. Goligher reports receiving personal fees and research support in the form of equipment from Getinge. Dr. Brodie is on the medical advisory boards for Baxter, BREETHE, and Hemovent, and past medical advisory board member for ALung Technologies. He currently serves on the Trial Steering Committee for the VENT-AVOID trial sponsored by ALung Technologies. Dr. Ferguson reports receiving personal fees from Getinge, Baxter, and Sedana Medical. Dr. Slutsky reports receiving personal fees from Getinge, Baxter, and Novalung/Xenios.

\section{Publisher's Note}

Springer Nature remains neutral with regard to jurisdictional claims in published maps and institutional affiliations.

Received: 9 May 2019 Accepted: 18 July 2019

Published online: 20 August 2019

\section{References}

1. Nin N, Muriel A, Peñuelas O et al (2017) Severe hypercapnia and outcome of mechanically ventilated patients with moderate or severe acute respiratory distress syndrome. Intens Care Med 43:200-208. https://doi. org/10.1007/s00134-016-4611-1

2. Laffey JG, Bellani G, Pham T et al (2016) Potentially modifiable factors contributing to outcome from acute respiratory distress syndrome: the LUNG SAFE study. Intens Care Med 42:1865-1876. https://doi.org/10.1007/ s00134-016-4571-5

3. Morelli A, Sorbo L, Pesenti A et al (2017) Extracorporeal carbon dioxide removal (ECCO2R) in patients with acute respiratory failure. Intens Care Med 43:519-530. https://doi.org/10.1007/s00134-016-4673-0

4. Bein T, Weber-Carstens S, Goldmann A et al (2013) Lower tidal volume strategy $\left(\approx 3 \mathrm{ml} / \mathrm{kg}\right.$ ) combined with extracorporeal $\mathrm{CO}_{2}$ removal versus "conventional" protective ventilation $(6 \mathrm{ml} / \mathrm{kg})$ in severe ARDS: the prospective randomized Xtravent-study. Intens Care Med 39:847-856. https ://doi.org/10.1007/s00134-012-2787-6

5. Sklar MC, Beloncle F, Katsios CM et al (2015) Extracorporeal carbon dioxide removal in patients with chronic obstructive pulmonary disease: a systematic review. Intens Care Med 41:1752-1762. https://doi. org/10.1007/s00134-015-3921-z

6. Goligher EC, Amato MBP, Slutsky AS (2017) Applying precision medicine to trial design using physiology. Extracorporeal $\mathrm{CO}_{2}$ removal for acute respiratory distress syndrome. Am J Respir Crit Care Med 196:558-568. https ://doi.org/10.1164/rccm.201701-0248CP

7. Combes A, Fanelli V, Pham T et al (2019) Feasibility and safety of extracorporeal $\mathrm{CO}_{2}$ removal to enhance protective ventilation in acute respiratory distress syndrome: the SUPERNOVA study. Intens Care Med 369:1-9. https ://doi.org/10.1007/s00134-019-05567-4

8. Sinha P, Calfee CS, Beitler JR et al (2018) Physiological analysis and clinical performance of the ventilatory ratio in acute respiratory distress syndrome. Am J Respir Crit Care Med 1:1. https://doi.org/10.1164/ rccm.201804-06920c

9. Gattinoni L Tonetti T Cressoni M et al (2016) Ventilator-related causes of lung injury: the mechanical power. Intens Care Med 42:1567-1575. https ://doi.org/10.1007/s00134-016-4505-2

10. Karagiannidis C, Strassmann S, Brodie D et al (2017) Impact of membrane lung surface area and blood flow on extracorporeal $\mathrm{CO}_{2}$ removal during severe respiratory acidosis. Intens Care Med Exp 5:1-13. https://doi. org/10.1186/s40635-017-0147-0

11. Amato MBP, Meade MO, Slutsky AS et al (2015) Driving pressure and survival in the acute respiratory distress syndrome. N Engl J Med 372:747755. https://doi.org/10.1056/NEJMsa1410639

12. I washyna TJ, Burke JF, Sussman JB et al (2015) Implications of heterogeneity of treatment effect for reporting and analysis of randomized trials in critical care. Am J Respir Crit Care Med 192:1045-1051. https://doi. org/10.1164/rccm.201411-2125CP

13. Bhatt DL, Mehta C (2016) Adaptive designs for clinical trials. N Engl J Med 375:65-74. https://doi.org/10.1056/NEJMra1510061

14. Freidlin B, Korn EL (2014) Biomarker enrichment strategies: matching trial design to biomarker credentials. Nat Rev Clin Oncol 11:81-90. https://doi. org/10.1038/nrclinonc.2013.218

15. Cressoni M, Gotti M, Chiurazzi C et al (2016) Mechanical power and development of ventilator-induced lung injury. Anesthesiology 124:11001108. https://doi.org/10.1097/ALN.0000000000001056

16. Goligher EC, Kavanagh BP, Rubenfeld GD, Ferguson ND (2015) Physiologic responsiveness should guide entry into randomized controlled trials. Am J Respir Crit Care Med 192:1416-1419. https://doi.org/10.1164/ rccm.201410-1832CP 
17. Terragni PP, Filippini C, Slutsky AS et al (2013) Accuracy of plateau pressure and stress index to identify injurious ventilation in patients with acute respiratory distress syndrome. Anesthesiology 119:880-889. https ://doi.org/10.1097/ALN.0b013e3182a05bb8

18. Kacmarek RM, Villar J, Sulemanji D et al (2016) Open lung approach for the acute respiratory distress syndrome: a pilot. Random Controll Trial 44:32-42. https://doi.org/10.1097/CCM.0000000000001383
19. Hager DN, Krishnan JA, Hayden DL et al (2005) Tidal volume reduction in patients with acute lung injury when plateau pressures are not high. Am J Respir Crit Care Med 172:1241-1245. https://doi.org/10.1164/ rccm.200501-048CP

20. Berry DA (2006) Bayesian clinical trials. Nat Rev Drug Discov 5:27-36. https://doi.org/10.1038/nrd1927 